Dossiê: Conferência de Medellín: 50 anos - Artigo Original

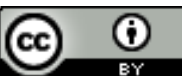

\title{
Medellín - Centralidade dos pobres na Igreja: clamores e resistências atuais
}

\author{
Medelín - Centrality of the poor in the church: clamors and current \\ resistances
}

Francisco de Aquino Júnior*

\begin{abstract}
Resumo
O artigo trata da característica mais importante da Conferência de Medellín (centralidade dos pobres na Igreja) e de sua atualidade (clamores e resistências atuais). Começa mostrando como o processo de recepção do Concilio Vaticano II na América Latina se dá a partir da Constituição Pastoral Gaudium et Spes e sua incipiente teologia dos "sinais dos tempos" mediante processo de inserção da Igreja na realidade latino-americana e de compromisso com os pobres e marginalizados e suas lutas por libertação. Em seguida, trata da atualidade desse dinamismo eclesial, indicando alguns ecos e/ou expressões atuais (antigos e novos) dos clamores e das resistências dos pobres e marginalizados em nosso continente - "sinal dos tempos" por excelência ao qual a Igreja deve estar sempre atenta, com o qual deve se envolver visceralmente e a serviço do qual deve se entregar com todas as suas forças.
\end{abstract}

Palavras-chave: Medellín; América Latina; sinal dos tempos; pobres; libertação.

\begin{abstract}
The article deals with the most important characteristic of the Medellin Conference (the centrality of the poor in the Church) and its relevance (present clamor and resistance). It begins by showing how the process of reception of the Second Vatican Council in Latin America comes from the Pastoral Constitution Gaudium et Spes and its incipient theology of the "signs of the times" through a process of insertion of the Church in Latin American reality, its commitment with the poor and marginalized, as well as their struggles for liberation. Next, the text deals with the current relevance of such ecclesial dynamism, by indicating some echoes and / or present expressions (old and new ones) of the cries and resistances of the poor and marginalized in our continent -a sign of the times par excellence, to which the Church needs to be always attentive and with which it must viscerally be involved and in the service of which it must place itself with all its strength.
\end{abstract}

Keywords: Medellín; Latin America; sign of the times; poor; liberation.

\footnotetext{
Artigo recebido em 06 de julho de 2018 e aprovado em 28 de agosto de 2018.

* Doutor em Teologia - Westfälische Wilhelms Universität Münster (2009). Atualmente é efetivo da Faculdade Católica de Fortaleza (FCF) e da Universidade Católica de Pernambuco (UNICAP). País de origem: Brasil. E-mail: axejun@yahoo.com.br
}

Horizonte, Belo Horizonte, v. 16, n. 50, p. 576-599, maio/ago. 2018 - ISSN 2175-5841 


\section{Introdução}

A celebração dos 50 anos da Conferência de Medellín tem sido uma ocasião privilegiada para revisitar seus textos, explicitar sua importância histórica e, sobretudo, para reafirmar e atualizar crítica e criativamente seu legado teológicopastoral.

Sobre Medellín se disse e se escreveu muitas coisas importantes que nem é preciso nem é possível repetir aqui (BOFF, C., 1988, p. 568-575; CALIMANN, 1999, p. 163-180; GUTIÉRREZ, 2010, p. 237-252; CATÃO, 2010, p. 253-284; GODOY AQUINO JÚNIOR, 2017; SOUSA - SBARDELOTTI, 2018; AQUINO JÚNIOR, 2018a, p. 41-58; CODINA, 2018, p. 59-76). Não há dúvida de que Medellín foi o "maior evento eclesial na história da Igreja da América Latina e do Caribe" (BEOZZO, 2018, p. 9) e que "representa um momento decisivo na história da Igreja em nosso continente" (FRANÇA MIRANDA, 2018, p. 42): "Nascida no impulso do Concílio, estava destinada a marcar um antes e um depois na vida da Igreja deste continente" (GUTIÉRREZ, 2010, p. 27). Como bem afirmava a presidência do CELAM na apresentação da versão oficial do Documento Final, Medellín foi "um autêntico pentecostes para a Igreja da América Latina” e marca um "novo período" na vida de nossa Igreja: um "período marcado por uma profunda renovação espiritual, por generosa caridade pastoral e por uma autêntica sensibilidade social” (CELAM, 2010, p. 6).

Mas há um ponto fundamental e determinante ao qual é preciso voltar sempre, sem o qual não se pode compreender a importância eclesial e social de Medellín e sobre o qual nunca se diz o bastante: a centralidade dos pobres na Igreja. A novidade e o impacto de Medellín na América Latina e, mesmo, no conjunto da Igreja estão radicalmente vinculados ao que, sobretudo a partir de Puebla, convencionou-se chamar “opção preferencial pelos pobres” e que Aparecida caracteriza como "uma das peculiaridades que marca a fisionomia da Igreja latinoamericana e caribenha" (CELAM, 2007, n. 391). 
E é sobre este ponto que vamos refletir. Primeiro, mostrando como é o ponto mais fundamental e mais determinante de Medellín. Segundo, tratando de sua atualidade ou de como ele se configura hoje a partir dos clamores e das resistências dos pobres e marginalizados em nosso continente. Desta forma, Medellín aparece não como um evento passado a ser deixado no passado ou, na melhor das hipóteses, nos arquivos e nos livros de história, mas como algo plenamente atual que nos interpela e nos obriga a um processo crítico-criativo de sua atualização histórica.

\section{Centralidade dos pobres na Igreja}

É verdade que não se pode entender Medellín sem o Vaticano II. Ela foi pensada e gestada como recepção do Concílio na América Latina. Nesse sentido, ela é filha e fruto do Concílio e pressupõe todo processo (complexo e conflitivo) de renovação teológico-pastoral desenvolvido e desencadeado neste acontecimento que marcou decisivamente a vida de nossa Igreja. Mas não se trata de uma tradução ou aplicação mecânica do Concílio na Igreja latino-americana (se é que isso é possível...). Trata-se, antes e mais radicalmente, de um processo de recepção criativa (CALIMANN, 1999, p. 169-172; FAGGIOLI, 2013, p. 86; VILLAS BOAS MARCHINI, 2018, p. 110-121; PASSOS, 2018, p. 122-147), no qual o dinamismo eclesial desencadeado pelo Concílio vai sendo assumido e se tornando realidade no contexto específico de um continente marcado por profundas desigualdades sociais e por um processo crescente de tomada de consciência do caráter injusto dessa situação e de organização e luta por sua superação e/ou transformação.

Esse processo de recepção criativa se dá fundamentalmente a partir de uma inserção da Igreja na realidade latino-americana e de um compromisso com os pobres e marginalizados e suas lutas por libertação. Isso significa dizer que a recepção do Concílio entre nós se dá (1) a partir da intuição e do projeto original de João XXIII de diálogo da Igreja com o mundo que encontrou sua melhor expressão na Constituição Pastoral Gaudium et Spes e sua teologia dos "sinais dos tempos" e (2) de sua concretização histórica em termos de opção pelos pobres. São as duas 
características mais importantes e mais determinantes do processo de recepção do Concílio na América Latina que convém examinar com mais atenção.

\subsection{Inserção na realidade latino-americana}

Vários autores têm chamado atenção para a importância fundamental e decisiva da Constituição Pastoral Gaudium et Spes e sua (insipiente, mas fecunda) teologia dos "sinais dos tempos" na Conferência de Medellín e em todo o processo de recepção do Concílio na América Latina (GUTIÉRREZ, 2010, p. 238-244; CODINA, 2013, p. 84; 2017, p. 303; 2018, p. 65-67; COSTADOAT, 2017, p. 110-115; BEOZZO, 2018, p. 10). Nas palavras de Victor Codina: “A novidade genial de Medellín foi abordar a eclesiologia do Vaticano II não a partir da Lumen Gentium, como fez grande dos bispos e teólogos europeus do pós-concílio” (CODINA, 2018, p. 65), "mas da Gaudium et Spes e da teologia dos sinais dos tempos, que constitui a originalidade maior do Vaticano II e do que João XXIII desejava do Concílio” (CODINA, 2017, p. 303).

Isso já aparece claramente no tema da conferência: "Presença da Igreja na atual transformação da América Latina”. É afirmado com muita clareza na introdução do Documento Final: começa afirmando que "a Igreja latinoamericana, reunida na II Conferência Geral de seu Episcopado, situou no centro de sua atenção o homem deste continente que vive um momento decisivo de seu processo histórico” e, com isso, "não se acha 'desviada', mas 'voltou-se' para o homem, consciente de "para conhecer Deus é necessário conhecer o homem"; fala do "momento histórico" vivido na América Latina (anseio de emancipação e de libertação) e o interpreta como um "evidente signo do Espírito"; e termina reafirmando que toda "reflexão [da conferência] orientou-se para a busca de forma de presença mais intensa e renovada da Igreja na atual transformação da América Latina à luz do Concílio Vaticano II" (CELAM, 2010, p. 37, 41). E, não por acaso, a primeira parte do documento está dedicada à problemática da promoção humana (justiça, paz, família e demografia, educação, juventude). 
Mas assumir o Concílio a partir da Gaudium et Spes e da teologia dos "sinais dos tempos" é uma possibilidade e uma opção nada evidentes nem tranquilas. Tanto é verdade que não foi esse o caminho tomado pela maioria das Igrejas (uma possibilidade entre outras) e que todas as grandes controvérsias eclesiais pósconcílio estão ligadas à essa problemática (caráter conflitivo dessa opção) (ALBERIGO, 2006, p. 179).

Se é verdade que a Gaudium et Spes, como disse o cardeal Gabriel-Marie Garrone, relator final do texto, ao apresenta-lo para a aprovação da assembleia conciliar, era o "único esquema querido formalmente por João XXIII" (Apud PALÁCIO, 1995, p. 333) e isso se pode comprovar sem dificuldades no discurso inaugural do Concílio Gaudet Mater Ecclesia (JOÃO XXIII, 2007, p. 27-35), não é menos verdade que é um dos, senão o texto mais controverso do Concílio e sobretudo de seu processo de recepção eclesial: seja por sua novidade epistemológica, seja pela complexidade e imprecisão teológicas do conceito "sinal dos tempos" (SCHICKENDANTZ, 2018, p. 1333-158; 2017, p. 33-69), seja por seu otimismo excessivo em relação ao mundo moderno (RATZINGER, 1985, p. 439472).

Em sua obra famosa sobre a "luta pelo sentido" do Vaticano II, Massimo Faggioli afirma que a "relação entre Igreja e mundo" é "a questão central do Concílio" e que as controvérsias e divisões em torno dessa questão, sobretudo no pós-concílio, são ainda maiores e vão muito além da clássica divisão entre conservadores e progressistas durante o concílio, na medida em que atinge e divide, inclusive, a chamada ala progressista do Concílio entre o que, com Joseph Komonchak, denomina "tendência neoagostiniana" e "tendência neotomista" (FAGGIOLI, 2013, p. 102-131).

Joseph Ratzinger, por exemplo, afirma que a Gaudium et Spes foi o documento "mais difícil e também o de maior êxito", que, "em razão de sua forma e da orientação de suas afirmações, é o que mais se afasta da história anterior dos concílios e permite perceber, por tanto, melhor que todos os demais textos, a 
peculiar fisionomia do último concílio", que foi "considerado como o autêntico testamento conciliar" e que "a penumbra que até ainda reina em torno da questão do autêntico sentido do Vaticano II depende destes diagnósticos e, portanto, também deste documento". No fundo, trata-se de saber se o Concílio deve ser interpretado a partir e em função do diálogo com o mundo $(G S)$ ou das declarações dogmáticas sobre a Igreja e a revelação ( $L G, D V)$ (RATZINGER, 1985, p. 453). Sem falar do excessivo otimismo em relação ao mundo moderno: "Se se deseja emitir um diagnóstico global sobre este texto, poderia dizer-se que ele significa (junto com os textos sobre a liberdade religiosa e sobre as religiões mundiais) uma revisão do Syllabus de Pio IX, uma espécie de Antisyllabus” (RATZINGER, 1985, p. 457).

Mas as dificuldades e resistências com esse documento não são exclusivas de Ratzinger. São comuns a muitos bispos e teólogos, particularmente ao bloco alemão. Como bem mostrou Carlos Schickendantz, no contexto mais amplo da controvérsia franco-alemã, mesmo um Karl Rahner, ainda que com diferenças significativas, expressou muitas reservas a este documento, sobretudo no que diz respeito a seus pressupostos e suas implicações epistemológicas. Chegou, inclusive, a escrever um texto com observações críticas sobre o esquema da futura constituição pastoral que foi usado pelo cardeal Döpfiner e incluído como material conciliar (SCHICKENDANTZ, 2018, p. 133-148).

Em todo caso - e não obstante a complexidade da problemática, os debates teológicos acerca de suas imprecisões e indeterminações epistemológicas e conceituais e as reservas críticas em relação ao otimismo conciliar frente ao mundo moderno - esse foi o caminho tomado pela Igreja da América Latina em Medellín. Sua recepção do Concílio se deu em forma de abertura e inserção na realidade latino-americana.

\subsection{Opção pelos pobres}

Mas o propósito fundamental do Concílio de abertura ao mundo e discernimento dos "sinais dos tempos" assumido por Medellín adquire 
características muito peculiares na América Latina com repercussões enormes no conjunto da Igreja.

Nas palavras de Gustavo Gutiérrez, "discernir os sinais dos tempos conduz a Conferência de Medellín a olhar de frente para a realidade de um continente que vive 'sob o signo do subdesenvolvimento", a considerar que "essa situação de pobreza é o maior desafio ao qual se deve fazer frente no anúncio do Evangelho nestas terras" e a convocar os cristãos a se "comprometerem na construção de uma sociedade justa sem marginalizados nem oprimidos" (GUTIÉRREZ, 2010, p. 245).

Nas palavras de Victor Codina,

O escutar e discernir os sinais dos tempos na América Latina à luz do Evangelho conduz a uma atitude de solidariedade com os pobres em vista de um desenvolvimento e uma promoção integral como fruto de sua missão salvífica, já que a salvação na América Latina abarca a libertação do homem todo, a passagem de condições menos humanas a condições mais humanas, um desenvolvimento em que o povo seja sujeito. (CODINA, 2018, p. 67).

E isso aparece claramente já na introdução do Documento Final ao interpretar os anseios e esforços por transformação, emancipação e libertação como um "evidente signo do Espírito que conduz a história dos homens e dos povos para sua vocação" ou como "presença de Deus que quer salvar o homem inteiro, alma e corpo" ou como antecipação escatológica da redenção/ressureição. Neste contexto se insere uma das afirmações mais importantes de Medellín e mais determinantes de todo dinamismo teológico-pastoral por ela inaugurado e/ou desencadeado:

Assim, como outrora Israel, o antigo povo, sentia a presença salvífica de Deus quando o libertava da opressão do Egito, quando o fazia atravessar o mar e o conduzia à conquista da terra prometida, assim também nós, novo povo de Deus, não podemos deixar de sentir seu passo que salva, quando se dá o "verdadeiro desenvolvimento que é, para cada um e para todos, a passagem de condições de vida menos humanas [carências materiais e morais, estruturas opressoras] para condições mais humanas [posse do necessário, conhecimentos, cultura, dignidade, espírito de pobreza, bem comum, paz, Deus, fé]”. (CELAM, 2010, p. 38-40).

Horizonte, Belo Horizonte, v. 16, n. 50, p. 576-599, maio/ago. 2018 - ISSN 2175-5841 
Dessa forma, Medellín assume a perspectiva fundamental do Vaticano II de abertura ao mundo e discernimento dos "sinais dos tempos" a partir dos pobres e seus anseios e lutas por libertação e, assim, retoma a intuição de João XXIII e de um grupo de padres conciliares de uma "Igreja dos pobres" e supera o eurocentrismo e o otimismo excessivo com a modernidade que caracterizam o Concílio.

Ao tratar os "sinais dos tempos" em termos de realidade social e, mais concretamente, em termos de transformação ou libertação (CCELAM, 2010, p. 120), Medellín retoma e desenvolve a intuição de João XXIII de uma "Igreja dos pobres” (JOÃO XXIII, 2007, p. 26). Essa intuição foi assumida por um grupo de padres conciliares que, embora exercendo uma pressão espiritual e profética significativa, permaneceu sempre à margem do Concílio e teve uma repercussão muito tímida nos documentos aprovados (GAUTHIER, 1967; 1969). Mas esse grupo ajudou a recuperar e dar visibilidade ao que o Cardeal Lercaro de Bolonha denominou um aspecto "essencial e primordial” da revelação e da fé e pôs em marcha um processo de renovação da Igreja a partir de sua relação essencial com os pobres. E, não obstante as tensões e controvérsias cada vez mais intensas, esse será o ponto mais fundamental e mais determinante do processo de recepção do Concílio na América Latina a partir de Medellín. Abertura ao mundo e "sinais dos tempos" entre nós têm a ver fundamentalmente com o que, sobretudo a partir de Puebla, será formulado cada vez mais em termos de "opção preferencial pelos pobres". Medellín vincula de tal modo "sinal dos tempos" e compromisso com os pobres que os pobres aparecerão cada vez mais como o "sinal dos tempos” por excelência ${ }^{1}$.

\footnotetext{
${ }^{1}$ Convém recordar aqui com Jon Sobrino que "toda teologia se confrontou muito centralmente com o momento negativo da existência humana e da história dos seres humanos [pecado e culpa, condenação eterna, morte, enfermidade, escravidão, sem-sentido, pobreza, injustiça etc.] E confrontar-se com essa negatividade é essencial à teologia, pois não se compreende a mensagem positiva da fé que pretende elaborar senão em relação à negatividade [...] De fato, isso sempre ocorreu na história da teologia. O que tem variado é a determinação de qual seja em um determinado momento a negatividade mais central, aquela que melhor introduz, a partir do negativo, na totalidade da teologia [...] O que a teologia da libertação faz é determinar qual é hoje a negatividade fundamental [...] o sofrimento massivo, cruel, injusto e durador produzido pela pobreza no Terceiro Mundo" (SOBRINO, 1992, p. 51).
}

Horizonte, Belo Horizonte, v. 16, n. 50, p. 576-599, maio/ago. 2018 - ISSN 2175-5841 
Certamente, há muitos sinais da presença de Deus no mundo e é preciso estar atento a eles e discerni-los. Mas, como diz Ignacio Ellacuria, em cada tempo há um sinal que é o principal, sob cuja luz deve-se discernir e interpretar todos os demais. Esse sinal é sempre o povo historicamente crucificado que junta à sua permanência a forma histórica sempre distinta de sua crucificação. Esse povo é a continuação histórica do servo de Yahve a quem o pecado do mundo continua tirando toda imagem humana, a quem os poderes deste mundo continua despojando de tudo, continua arrebatando até a vida, sobretudo a vida” (ELLACURIA, 2000a, p. 134).

Essa redescoberta da centralidade dos pobres na Igreja, formulada em termos de "Igreja dos pobres" ou de “opção pelos pobres”, acabou revelando e superando limites e ambiguidades do próprio Concílio: "um Concílio universal, mas na perspectiva dos países ricos e da chamada cultura ocidental" (ELLACURIA, 200ob, p. 173) e, por isso mesmo, um Concílio pouco profético (COMBLIN, 2009, p. 185) e um Concílio que acabou nos legando "uma igreja de classe média" (TURSI - FRENCKEN, 2008, p. 142).

Se o Concílio teve o mérito incalculável de descentrar a Igreja, de abri-la e lançá-la ao mundo, "não historicizou devidamente o que era esse mundo, um mundo que devia ter definido como um mundo de pecado e injustiça, no qual as imensas maiorias da humanidade padecem de miséria e injustiça” (ELLACURÍA, 200oc, p. 449). Não bastava abrir-se ao mundo. Era necessário determinar com maior clareza e precisão que mundo era esse (mundo estruturalmente injusto e opressor) e qual o lugar social da Igreja nesse mundo (mundo dos pobres e oprimidos) (BEOZZO, 2018, p. 10). Aqui reside um dos maiores limites do Concílio. E aqui residem, indiscutivelmente, a força e a insuperabilidade de Medellín.

A Igreja que nasce em Medellín é verdadeiramente uma "Igreja dos pobres" (SOBRINO, 1982; BOFF, L, 1991; AQUINO JÚNIOR, 2018b): uma Igreja pobre, uma Igreja faz “opção pelos pobres”, uma Igreja que assume as causa dos pobres, uma Igreja de profetas e mártires que dão a vida pelos pobres, enfim, a Igreja de 
Jesus de Nazaré... E essa Igreja ganha novo impulso e vigor com o papa Francisco e seu empenho evangélico por uma "Igreja pobre e para os pobres" ou por uma "Igreja em saída para as periferias do mundo".

\section{Clamores e Resistências Atuais}

A característica mais importante e mais fundamental da Igreja que nasce em Medellín é sua inserção no mundo dos pobres e marginalizados. É verdade que muita coisa mudou de Medellín para cá. Tanto no que diz respeito à realidade social e eclesial, quanto no que diz respeito aos clamores e resistências dos pobres. E isso tem muitas implicações para a ação pastoral/evangelizadora da Igreja. Não no sentido dos pobres perderem a centralidade na Igreja (isso seria trair e renegar o Evangelho de Jesus Cristo!), mas na forma de inserção da Igreja no mundo dos pobres. Por essa razão, a Igreja precisa está muito atenta, em cada tempo e lugar,

para escutar, perceber e discernir nos clamores e nas resistências dos pobres e marginalizados os sinais do Espírito do Senhor que "atua a partir de baixo" (CODINA, 2015). Nunca pode dar isso por suposto. A realidade é muito mais complexa e dinâmica do que parece.

Nesse sentido, mas sem nenhuma pretensão de exaustão e desenvolvimento, indicaremos a seguir alguns ecos e expressões de clamores e resistências atuais (antigos e novos) dos pobres e marginalizados.

\subsection{Clamores dos pobres e marginalizados}

Medellín nasce da escuta atenta do "surdo clamor" e do "grito que sobe do sofrimento" das maiorias pobres e marginalizadas de nosso continente (CELAM, 2010, p. 195). E, sempre de novo, é preciso escutar esse "surdo clamor" e esse "grito que sobe do sofrimento"; clamor/grito ligado a distintas formas de injustiça, marginalização e indiferença.

a) Antes de tudo, a profunda desigualdade social que caracteriza nosso continente e nosso mundo: uma "injustiça que clama ao céu” (CELAM, 2010, p. 
45). Em Medellín, tornou-se comum falar de "estruturas injustas", de "situação de injustiça", de "violência institucionalizada", bem como da necessidade e urgência de "mudança de estrutura", de "novas e renovadas estruturas", de uma "ordem social justa”. A palavra de ordem era: transformação da sociedade. E isso mobilizou amplos setores da Igreja e da sociedade. Hoje, curiosamente, muita gente tem escrúpulo de falar de transformação da sociedade, de transformação das estruturas. Amplos setores da esquerda, por razões as mais diversas, reduzindo a política à "arte do possível", acabaram reduzindo a pauta política da esquerda, contentandose com políticas sociais afirmativas (importantes e necessárias, sem dúvida!) e fortalecendo a tese de que não é possível nenhuma transformação mais profunda da sociedade (SAFATLER, 2014). Enquanto isso, e sob o domínio do "capital improdutivo", a desigualdade social cresce assustadora e desenfreadamente: 0,7\% da população mundial detém 40,6\% da riqueza total do mundo, enquanto 73,2\% detém apernas 2,4\%; 1\% da população tem mais riqueza do que 99\% restante do planeta; 8 indivíduos detém a mesma riqueza que a metade mais pobres do mundo; entre 1988 e 2011, a renda dos 10\% mais pobres aumentou cerca de US\$ 65, enquanto a renda do 1\% mais rico aumentou cerca de US\$11.800, ou seja, 182 vezes mais (DOWBOR, 2017, p. 27). E, nesse ponto, a situação de nossos países não é muito diferente, mesmo quando tenha havido melhorias significativas da qualidade de vida das populações pobres².

b) Junto à desigualdade social, tão destacada em Medellín e apontada pelo papa Francisco como a "raiz dos males social" (PAPA FRANCISCO, 2013, n. 202), a Igreja latino-americana foi percebendo pouco a pouco, a partir das dores, dos gritos e das lutas de mulheres, indígenas, negros e pessoas LGBTs, outras formas de opressão, dominação, colonialismo e exclusão que, embora na maioria das vezes esteja associada à desigualdade socioeconômica, não se restringem a ela: o machismo/patriarcalismo que se materializa em diferentes formas de dominação, violência e marginalização e que está na raiz do crescente feminicídio que tem

${ }^{2}$ Para o caso específico do Brasil, ver Venturini (2017).

Horizonte, Belo Horizonte, v. 16, n. 50, p. 576-599, maio/ago. 2018 - ISSN 2175-5841 
ceifado a vida de tantas mulheres; o etnocentrismo que provocou verdadeiros genocídios e etnocídios em nosso continente e que continua negando aos povos indígenas o direito a seus territórios e tratando suas culturas com seus modos de vida, com suas sabedorias e tradições religiosas como atraso, superstição e empecilho ao desenvolvimento e ao progresso; o racismo que escravizou e assassinou milhares de negros, que demonizou suas culturas e tradições religiosas, que os "libertou" das senzalas para viver na miséria e que, camuflado pela falsa democracia racial, continua marginalizando o povo negro a ponto de “ofender/diminuir alguém" ter se tornado em nossa cultura sinônimo de "tratar como negro" (denegrir); e a homofobia que tem causado tanto sofrimento interior, tanto preconceito e exclusão social e eclesial, tanta violência psíquica, espiritual, verbal e física e, cada vez mais, o assassinato cotidiano (com requintes de crueldade) a pessoas LGBTs.

c) A esses gritos foi se juntando cada vez mais o grito da natureza, espoliada e reduzida a recurso e/ou instrumento de acumulação de capital, com consequências drásticas para os pobres que vivem nas periferias e áreas de riscos e para as futuras gerações. Entre nós, na América Latina, Leonardo Boff tem ajudado muito no processo de consciência e mobilização socioambientais a partir da escuta do grito da terra. Sua contribuição mais importante e seu mérito maior nesse processo têm a ver com a percepção de que o grito da terra é inseparável do grito dos pobres e, vice-versa, que o grito dos pobres é inseparável do grito da terra. Ele tem ajudado a construir uma compreensão de ecologia que articula o grito da terra com o grito dos pobres. Aliás, esse é o título de sua obra mais importante sobre a problemática socioambiental: Ecologia: grito da terra, grito dos pobres (BOFF, L, 2015). Na mesma direção, um marco importante na escuta do grito da terra no grito do pobre foi a Encíclica Laudato Si’ do Papa Francisco Sobre o cuidado da casa comum em 2015 (PAPA FRANCISCO, 2015a; MURAD - TAVARES, 2016). Criticando toda forma de "antropocentrismo despótico" (PAPA FRANCISCO, 2015a, n. 68) e de "biocentrismo" cínico (PAPA FRANCISCO, 2015a, n. 118), Francisco propõe uma ecologia integral que tem como um de seus eixos 
fundamentais "a relação intima entre os pobres e a fragilidade do planeta” (PAPA FRANCISCO, 2015a, n. 16). Daí sua insistência em que "uma verdadeira abordagem ecológica sempre se torna uma abordagem social, que deve integrar a justiça nos debates sobre o meio ambiente, para ouvir tanto o clamor da terra como o clamor dos pobres” (PAPA FRANCISCO, 2015a, n. 49; n. 53, p. 117).

d) O recrudescimento da violência física direta, ligado a fatores de ordem econômica, social, cultural, psicológica e aliado ao poder do tráfico e ao crescimento do crime organizado, com índices alarmantes de assassinatos nas periferias de nossas cidades e entre as "chamadas" minorias sociais3, é um lamento/grito que a cada dia ecoa com mais força e intensidade no extermínio da juventude pobre e negra de nossas periferias, na dor e no choro desesperado das mães que veem seus filhos assassinados ou que têm que abandonar seus barracos por ordem do tráfico e/ou para não serem executados, no feminicidio, no assassinato de pessoas LGBTs, no desprezo social, nas políticas de higienização urbana, na violência policial e no assassinato da população em situação de rua (só na cidade de São Paulo, são cerca de 16 mil pessoas), dentre outros. É verdade que a violência é um fenômeno complexo que não pode ser simplificado e reduzido à agressão físico-direta. Oscar Romero e Ignacio Ellacuría, em contexto de guerra, chamaram atenção para as diferentes formas de violência, sua hierarquização e sua mútua implicação (ROMERO, 2007a, p. 113-118; 2007b, 156-159; ELLACURIA, 1993, p. 712-732). E a Campanha da Fraternidade da Igreja do Brasil em 2018 Fraternidade e superação da violência - distinguiu três formas fundamentais de violência que se implicam mutuamente: violência direta, violência institucional e cultura da violência (CNBB, 2017, p. 15-24). Por mais que a raiz da violência seja de ordem institucional-cultural, é em sua forma de agressão física que ela é mais direta e intensamente sentida e é aí que de modo mais imediato e desesperado ecoa

${ }^{3}$ Para o caso específico do Brasil, ver Atlas da Violência 2018 (IPEA - FBSP, 2018).

Horizonte, Belo Horizonte, v. 16, n. 50, p. 576-599, maio/ago. 2018 - ISSN 2175-5841 
o grito das vítimas4, em sua imensa maioria: pobres-negros-mulheres-jovensLGBTs...

e) Toda essa situação vem produzindo um processo de des-solidarização humana, corroendo de maneira intensa e progressiva os vínculos societários e gestando um modo de vida que o papa Francisco chamou em sua exortação apostólica A alegria do Evangelho "cultura do descartável" (PAPA FRANCISCO, 2013, n. 53), "ideal egoísta” ou "globalização da indiferença” que nos torna “incapazes de nos compadecer ao ouvir os clamores alheios” (PAPA FRANCISCO, 2013, n. 54). Trata-se de um modo de vida centrado nos próprios interesses em que tudo, inclusive as pessoas, valem apenas e na medida em que nos são úteis e/ou nos causam algum prazer ou satisfação. Isso tem levado à indiferença ao sofrimento e aos dramas alheios, à banalização da vida humana, à naturalização e espetacularização midiática da violência, à indiferença ou mesmo ao apoio a práticas de linchamento coletivo e/ou extermínio de pessoas pela polícia ou por grupos paramilitares, à apologia à tortura e aos torturados, ao crescente apoio à pena de morte e à tese de que "bandido bom é bandido morto", ao crescimento eleitoral de candidatos militares com políticas de segurança centradas no encarceramento e na execução de pessoas pobres etc. E se isso tem consequências para o conjunto da sociedade, repercute de maneira direta e dramática na vida dos pobres por sua situação de vulnerabilidade social e incapacidade de fazer valer seus direitos fundamentais. Basta pensar no que essa "indiferença" ou cumplicidade social significa para as populações pobres das periferias ou que vivem nas ruas de nossas cidades, para os encarcerados ou para os imigrantes que tentam ganhar a vida na Europa ou, mais perto de nós, nos EUA...

\subsection{Resistências dos pobres e marginalizados}

Dizíamos que Medellín nasce da escuta atenta do "surdo clamor" e do "grito que sobe do sofrimento" das maiorias pobres e marginalizadas de nosso continente.

\footnotetext{
${ }^{4}$ A propósito da situação de El Salvador, ver Callizo; Schwab; Zechmeister (2017, p. 251-279).
}

Horizonte, Belo Horizonte, v. 16, n. 50, p. 576-599, maio/ago. 2018 - ISSN 2175-5841 
Escuta atenta que envolve, obriga e compromete. Daí que o dinamismo eclesial desencadeado por Medellín seja caracterizado radicalmente pela inserção no mundo dos pobres, pelo envolvimento com suas vidas e pelo compromisso com suas causas e suas lutas. Isso foi despertando e aguçando a sensibilidade da Igreja latino-americana para as mais diversas formas de resistência popular. E sempre de novo é preciso voltar a esse ponto: perceber e se envolver com o pulsar desesperado e criativo da vida nas diferentes formas de resistência e luta dos pobres e marginalizados.

a) Antes de tudo, a luta cotidiana pela sobrevivência. É a luta primeira e mais fundamental: a luta para viver, para continuar vivo. Uma verdadeira luta. Para muita gente, viver é uma luta e está vivo é uma conquista - um verdadeiro milagre. É preciso estar atento e perceber os caminhos e as formas que o povo encontra ou inventa para ganhar a vida e continuar vivendo: comer, morar, trabalhar, proteger-se, cuidar da saúde, criar os filhos, afirmar sua dignidade, defender seus direitos, ajudar os outros, festejar, viver a fé etc. Aquilo que Jon Sobrino chamava de "santidade primordial" ou "santidade do viver": "a ânsia de viver e sobreviver no meio de grandes sofrimentos, a decisão e os trabalhos para conseguir isso com criatividade sem limites, com fortaleza e com constância, desafiando inumeráveis dificuldades e obstáculos" (SOBRINO, 2002, p. 126) e “junto com impulso do próprio viver, surge também a força de solidariedade de uns com os outros [...] a solidariedade mais primária"; é a "decisão primária de viver e dar vida" (SOBRINO, 2002, p. 36, 37). Aquilo que o papa Francisco chama em sua Exortação Apostólica Gaudete et exsultate de santidade do dia-dia ou santidade ao "pé da porta", presente "nos pais que criam os seus filhos com tanto amor, nos homens e mulheres que trabalham a fim de trazer o pão para casa, nos doentes, nas consagradas idosas que continuam a sorrir" (PAPA FRANCISCO, 2018, n. 7) etc. É aqui se enraízam e se nutrem as mais diversas formas de resistência e luta populares. 
b) Em segundo lugar, o fortalecimento dos laços de solidariedade. Seja de modo mais espontâneo e pontual e até mesmo condicionado pela situação de necessidade comum: partilha entre vizinhos ou entre companheiros que vivem a mesma situação; cuidado dos doentes e das pessoas com necessidades especiais, indignação contra o preconceito e a violência, afetos, festa, partilha de vida etc. Seja pela afinidade familiar, comunitária, sexual, cultural e/ou afinidade no sofrimento. Seja em comunidades de fé, onde se alimenta a esperança e se encontra forças para enfrentar as dificuldades da vida na intimidade com o Senhor, na vida fraterna e no compromisso com os irmãos necessitados. Seja através de ONGs e/ou projetos sociais que reúnem pessoas, fortalecem os laços entre elas e, através de atividades lúdicas, artísticas, econômicas, sociais e religiosas, atendem a necessidades e direitos fundamentais, recuperam a autoestima das pessoas, liberam suas energias e capacidades criativas para sonhar e refazer a vida (AQUINO JÚNIOR, 2011, p. 197-212; 2014, p. 47-58; SANTIAGO, 2017). Certamente, há muita ambiguidade em tudo isso - e onde não há ambiguidade? Mas essas formas e esses espaços de solidariedade, com todas as suas contradições, têm sido fonte de vida e de esperança para muita gente e, se potencializadas social e politicamente, podem fazer avançar muito na luta e na conquista de direitos.

c) Em terceiro lugar, as lutas e organizações populares. Tanto em suas formas mais clássicas e institucionais: sindicatos, cooperativas, associações, organizações camponesas e operárias, greves, movimentos de massa, ocupações etc. Quanto em suas formas mais recentes mais ou menos pontuais e/ou espontâneas: novos sujeitos (indígenas, feministas, LGBTs, catadores de material reciclável, população de rua, estudantes, comunidades camponesas e das periferias urbanas etc.), novas formas de organização e mobilização (em torno de questões específicas e pontuais, articulação em redes, importância da emoção e do lúdico, sensibilidade a questões étnico-raciais e de gênero, redes sociais etc.) e novos horizontes utópicos que integrem melhor questões econômicas, ambientais, étnicoraciais, religiosas, de gênero etc. Essas lutas e organizações populares aprofundam os laços de solidariedade, alargam os horizontes da vida e dos direitos, qualificam 
as estratégias de luta, articulam, ampliam e fortalecem a força dos pequenos e sua capacidade de movimentar a sociedade para fazer valer seus direitos. Por isso mesmo, o papa Francisco em seus encontros mundiais com os movimentos populares (PAPA FRANCISCO, 2015b; 2015c; 2016; AQUINO JÚNIOR, 2018c) insistiu tanto na importância desses movimentos para o processo de transformação da sociedade: são portadores de uma "torrente de energia moral", "expressam a necessidade urgente de revitalizar nossas democracias", são "semeadores da mudança" e do "vento de promessa que reacende a esperança de um mundo melhor”, enfim, são "como uma benção para a humanidade”.

d) Em quarto lugar, os partidos políticos de esquerda. É um tema complexo, conflitivo e delicado, sobretudo no contexto atual de crise mundial das esquerdas e das tensões e divisões em torno das experiências de governos populares na América Latina; um tema que divide a própria esquerda, os movimentos sociais, a Igreja dos pobres e os setores progressistas em geral; mas um tema que precisa ser enfrentado com criticidade e criatividade, uma vez que diz respeito à regulamentação política da sociedade e que isso tem enormes consequências na vida povo. Certamente, já não há espaço para idealismos ingênuos com relação às possibilidades reais de transformação da sociedade através de partidos e governos. As experiências recentes mostraram os limites institucionais e políticos de sua atuação. Tampouco há espaço para instrumentalização e aparelhamento dos movimentos e organizações populares por partidos e governos. Também, aqui, as experiências recentes mostraram as consequências trágicas dessa prática equivocada e donosa em muitos setores da esquerda. Mas isso não pode levar, em hipótese nenhuma, a uma espécie de indiferença partidária nem muito menos a um antipartidarismo que só favorece aos interesses das elites. Partidos e governos nem são suficientes nem podem tudo, mas são importantes e são necessários. E a conjuntura atual exige da esquerda autocrítica em relação às experiências de governo e ousadia e criatividade na formulação e viabilização de projetos e estratégias políticos populares, o que só será possível mediante unidade das esquerdas (SANTOS, 2018) e disposição de construção e viabilização de um projeto político de esquerda, 
centrado na luta contra a desigualdade social e econômica e na soberania popular (SAFATLE, 2014).

e) Finalmente, em quinto lugar, a articulação continental e mundial das forças e organizações populares. Já existem muitas experiências nesse sentido: partidos, sindicatos, movimentos feministas, movimentos camponeses, movimentos indígenas, movimento dos catadores de material reciclável, movimento contra mineração, fórum social mundial etc. E, em tempos de globalização do capital e de expansão da lógica do mercado nas diversas dimensões e nos diferentes espaços da vida, é mais urgente ainda a globalização da solidariedade e da luta pela justiça. Se a globalização do mercado se faz a partir de cima e produz exclusão social, injustiça socioambiental e cultura da indiferença; a globalização da solidariedade se faz a partir de baixo e vai criando possibilidades de vida para os pobres e marginalizados, refazendo os vínculos sociais e criando uma cultura da solidariedade, centrada no bem comum e na justiça socioambiental. Nesse sentido, e mais do que nunca, é preciso e urgente fortalecer e ampliar os vínculos e as articulações entre as diversas forças populares em nível continental e mundial: partidos de esquerda, movimentos e organizações populares, Igreja dos pobres etc. Não podemos nos fechar em nossas regiões, em nossos movimentos e em nossas lutas. Até porque não estamos desconectados do mundo e o que acontece no local está muito mais determinado por fatores globais do que pode parecer. A injustiça é global e a luta contra a injustiça tem que ser também global. É claro que o global se materializa no local ou em situações particulares concretas e é ai que ele tem que ser enfrentado.

\section{Conclusão}

Falamos da importância da Constituição Pastoral Gaudium et Spes e de sua incipiente teologia dos "sinais dos tempos" no processo de recepção do Concílio Vaticano II em Medellín. Falamos de sua concretização em termos de inserção na realidade latino-americana e, mais concretamente, em termos de opção pelos 
pobres. E indicamos alguns ecos e/ou expressões atuais (antigos e novos) dos clamores e das resistências dos pobres e marginalizados em nosso continente “sinal dos tempos” por excelência ao qual devemos estar muito atentos, com o qual devemos nos envolver e a serviço do qual devemos entregar nossas vidas.

A pergunta que não quer calar é até que ponto os pobres e marginalizados com seus clamores e suas resistências continuam sendo a preocupação maior de nossa Igreja. Se isso já não tranquilo em Medellín e foi se tornando cada vez mais controverso nas décadas de 70 e 80, hoje, não obstante a insistência profética do papa Francisco, parece algo estranho em nossa Igreja que tem coisas mais “importantes" (mais "religiosas", mais “sagradas”, mais "espirituais”) para cuidar. Haveria que perguntar, inclusive, até que ponto os clamores e as resistências dos pobres e marginalizados estão no centro das preocupações e do quefazer teológicos na América Latina.

Em todo caso, e a modo de conclusão, queremos insistir com Medellín que

[...] não basta refletir, conseguir mais clarividência e falar. É necessário agir. A hora atual não deixou de ser a hora da palavra, mas já se tornou, com dramática urgência, a hora da ação. Chegou o momento de inventar com imaginação criadora a ação que cabe realizar e que, principalmente, terá de ser levada a cabo com a audácia do Espírito e o equilíbrio de Deus. (CELAM, 2010, p. 38).

Importa assumir, hoje, com todas as consequências teóricas e práticas a centralidade dos pobres na Igreja: suas vidas, seus clamores, suas esperanças, suas resistências e suas lutas. E convém recordar e insistir com o papa Francisco que isso "não é uma tarefa mais, mas talvez a mais importante porque 'os pobres são os destinatários privilegiados do Evangelho" (PAPA FRANCISCO, 2015d). Em suas vidas e em suas mortes, como afirmava São Romero, está em jogo a glória de Deus neste mundo: “A glória de Deus é o pobre que vive” (ROMERO, 2007c, p. 193). Que vivamos dessa glória e para essa glória...

Horizonte, Belo Horizonte, v. 16, n. 50, p. 576-599, maio/ago. 2018 - ISSN 2175-5841 


\section{REFERÊNCIAS}

ALBERIGO, Guiseppe. Breve história do Concílio Vaticano II. Aparecida: Santuário, 2006.

AQUINO JÚNIOR, F. Organizações populares. São Paulo: Paulinas, 2018c.

AQUINO JÚNIOR, Francisco. Tudo tem jeito. Só não tem jeito para a morte. A esperança que vem das ruas e dos lixões. In: A dimensão socioestrutural do reinado de Deus: escritos de teologia social. São Paulo: Paulinas, 2011. p. 197-212.

AQUINO JÚNIOR, Francisco. 50 anos de Medellín - 5 anos de Francisco: perspectivas teológico-pastorais. Perspectiva teológica, n. 50, p. 41-58, 2018a.

AQUINO JÚNIOR, Francisco. Entre ruas: fé e esperança de um povo. Espiritualidade da pastoral do povo da rua. In: Viver segundo o espírito de Jesus Cristo: espiritualidade como seguimento. São Paulo: Paulinas, 2014. p. 47-58.

AQUINO JÚNIOR, Francisco. Igreja dos pobres. São Paulo: Paulinas, 2018b.

BEOZZO, José Oscar. Prefácio. In: SOUSA, Ney; SBARDELOTTI, Emerson (Org.).

Medellín: memória, profetismo e esperança na América Latina. Petrópolis: Vozes, 2018. p. 9-18.

BOFF, Clodovis. A originalidade histórica de Medellín. Convergência, n. 317, p. 568-575, 1998.

BOFF, Leonardo. E a Igreja se fez povo. Eclesiogênese: a Igreja que nasce da fé do povo. Petrópolis: Vozes, 1991.

BOFF, Leonardo. Ecologia: grito da terra, grito dos pobres. Dignidade e direitos da Mãe Terra. Edição revisada e ampliada. Petrópolis: Vozes, 2015.

CALIMAN, Cleto. A trinta anos de Medellín: uma nova consciência eclesial na América Latina. Perspectiva Teológica, n. 31, p. 163-180, 1999.

CALLIZO, Jaime Comabella; SCHWAB, Benjamin Jonathan; ZECHMEISTER, Martha. Escuchar el grito de las víctimas: Impulsos desde la teología de la liberación. Revista Latinoamericana de Teología, n. 102, p. 251-279, 2017.

CATÃO, Francisco. Aos trinta anos de Medellín. In: Conclusões da Conferência de Medellín - 1968: trinta anos depois. Medellín ainda é atual? São Paulo: Paulinas, 2010. p. 253-284.

CELAM. Conclusões de Medellín. In: Conclusões da Conferência de Medellín 1968: trinta anos depois. Medellín ainda é atual? São Paulo: Paulinas, 2010. 
CELAM. Documento de Aparecida. São Paulo: Paulinas, 2007.

CNBB. Campanha da Fraternidade 2018: Texto-Base. Brasília: Edições CNBB, 2017.

CODINA, Victor. Hacer teologia en medio de los pobres. Revista Latinoamericana de Teología, n. 102, p. 301-309, 2017.

CODINA, Victor. La ponencias de Medellín. Perspectiva Teológica, n. 5o, p. 59-76, 2018.

CODINA, Victor. Las iglesias del continente 50 años después de Vaticano II: cuestiones pendientes. In: CONGRESO CONTINENTAL DE TEOLOGÍA (Org.). 50 años del

Vativano II: análisis y perspectivas. Bogotá: Paulinas, 2013. p. 81-92.

CODINA, Victor. El Espírito del Señor actua desde abajo. Sal Terrae, Maliaña, 2015.

COMBLIN, José. A profecia na igreja. São Paulo: Paulus, 2009.

COSTADOAT, Jorge. Hacia un nuevo concepto de revelación? La historia como lugar teológico en la teología de la liberación. In: AZGUY, Virginia Raquel; GARCÍA, Diego; SCHICKENDANTZ, Carlos (Ed.). Lugares e interpelaciones de Dios: discernir los signos de los tempos. Santiago de Chile: Universidad Alberto Hurtado, 2017. p. 105-132.

DOWBOR, Ladislau. A era do capital improdutivo. São Paulo: Outras Palavras, 2017.

ELLACURÍA, Ignacio. Comentarios a la Carta Pastoral. In: Escritos Políticos II: veite años de historia em el salvador (1969-1989). San Salvador: UCA, 1993. p. 679-732.

ELLACURÍA, Ignacio. Discernir “el signo” de los tempos. In: Escritos Teológicos II. San Salvador: UCA, 2000a, p. 133-135.

ELLACURÍA, Ignacio. El auténtico lugar social de la Iglesia. In: Escritos Teológicos II. San Salvador: UCA, 2000c, p. 439-451.

ELLACURIA, Ignacio. Pobres. In: Escritos Teológicos II. San Salvador: UCA, 20oob, p. 171-192.

FAGGIOLI, M. Vaticano II: a luta pelo sentido. São Paulo: Paulinas, 2013.

FRANÇA MIRANDA, Mario. A teologia de Medellín. In: SOUSA, Ney; SBARDELOTTI, Emerson (Org.). Medellín: memória, profetismo e esperança na américa latina.

Petrópolis: Vozes, 2018. p. 41-52.

GAUTHIER, Paul. O concílio a Igreja dos pobres. Petrópolis: Vozes, 1967.

GAUTHIER, Paul. O evangelho da justiça. Petrópolis: Vozes, 1969. 
GODOY, Manuel; AQUINO JÚNIOR, Francisco. (Org.). 50 anos de Medellín: revisitando os textos, retomando o caminho. São Paulo: Paulinas, 2017.

GUTIÉRREZ, Gustavo. Atualidade de Medellín. In: Conclusões da Conferência de Medellín - 1968: trinta anos depois. Medellín ainda é atual? São Paulo: Paulinas, 2010. p. 237-252.

IPEA - FBSP. Atlas da violência 2018. Disponível em:<http://www.ipea.gov.br/portal/images/stories/PDFs/relatorio_institucional/180604 _atlas_da_violencia_2018.pdf >. Acesso em: 10. ago. 2018.

JOÃO XXIII. Discurso do Papa João XXIII Gaudet Mater Ecclesia na abertura solene do Concílio. In: VATICANO II: mensagens, discursos e documentos. São Paulo: Paulinas, 2007. p. 27-35.

JOÃO XXIII. Mensagem radiofônica a todos os fieis católicos, a um mês da abertura do Concílio. In: VATICANO II: mensagens, discursos e documentos. São Paulo: Paulinas, 2007. p. 20-26.

MURAD, Afonso - TAVARES, Sinivaldo (Org.). Cuidar da casa comum: chaves de leitura teológicas e pastorais da laudato si’. São Paulo: Paulinas, 2016.

PALACIO, Carlos. O legado da Gaudium et Spes. Riscos e exigências de uma nova 'condição cristã. Perspectiva Teológica, n. 27, p. 333-353, 1995.

PAPA FRANCISCO. Visita ao bairro pobre de Kamgemi: discurso do santo padre (27/11/2015d). Disponível em:

<http://w2.vatican.va/content/francesco/pt/speeches/2015/november/documents/papafrancesco_20151127_kenya-kangemi.html>.Acesso em: 10.ago. 2018.

PAPA FRANCISCO. Carta Encíclica Laudato si' Sobre o cuidado da casa comum. São Paulo: Paulinas, 2015a.

PAPA FRANCISCO. Discurso do Papa Francisco aos participantes do Encontro Mundial dos Movimentos Populares. Brasília: CNBB, 2015b.

PAPA FRANCISCO. Discurso do Papa Francisco aos participantes do III Encontro Mundial dos Movimentos Populares. Brasília: CNBB, 2016.

PAPA FRANCISCO. Discurso do Papa Francisco no II Encontro Mundial dos Movimentos Populares. Brasília: CNBB, 2015c.

PAPA FRANCISCO. Exortação Apostólica Evangelii Gaudium: sobre o anúncio do evangelho no mundo atual. São Paulo: Paulinas, 2013.

PAPA FRANCISCO. Exortação Apostólica Gaudete et exsultate: sobre a chamada à santidade no mundo atual. São Paulo: Paulinas, 2018. 
PASSOS, João Décio. 50 anos de Medellín: Carisma vivo na história em mudança. In: SOUSA, Ney; SBARDELOTTI, Emerson (Org.). Medellín: memória, profetismo e esperança na américa latina. Petrópolis: Vozes, 2018. p. 122-147.

RATZINGER, J. Teoría de los principios teológicos: materiales para una teología fundamental. Barcelona: Herder, 1985.

ROMERO, Oscar. Iglesia y organizaciones políticas populares: Tercera Carta Pastoral. In: SOBRINO, Jon; MARTÍN-BARÓ, Ignacio; CARDENAL, Rodolfo. La voz de los sin voz: la palavra viva de monseñor romero. San Salvador: UCA, 2007a, p. 91-121.

ROMERO, Oscar. La dimensión politica de la fé desde la opción por los pobres. In: SOBRINO, Jon; MARTÍN-BARÓ, Ignacio; CARDENAL, Rodolfo. La voz de los sin voz: la palavra viva de monseñor romero. San Salvador: UCA, 2007c, 181-193.

ROMERO, Oscar. Misión de la Iglesia en médio de la crisis del país: Cuarta Carta Pastoral. In: SOBRINO, Jon; MARTÍN-BARÓ, Ignacio; CARDENAL, Rodolfo. La voz de los sin voz: la palavra viva de monseñor romero. San Salvador: UCA, 2007b, p. 123-172.

SAFATLER, Vladimir. A esquerda que não teme dizer seu nome. São Paulo: Três estrelas, 2014.

SANTIAGO, Adriana. (Org.). Esticadores de horizontes: narrativas juvenis sobre vidas reinventadas. Fortaleza: Expressão Gráfica e Editora, 2017.

SANTOS, Boaventura. Esquerdas do mundo, uni-vos! São Paulo: Boitempo, 2018.

SCHICKENDANTZ, Carlos. Signo de los tempos. Articulación entre princípios teológicos y acontecimientos históricos. In: AZGUY, Virginia Raquel; GARCÍA, Diego;

SCHICKENDANTZ, Carlos (Ed.). Lugares e interpelaciones de Dios: discernir los signos de los tempos. Santiago de Chile: Universidad Alberto Hurtado, 2017. p. 33-69.

SCHICKENDANTZ, Carlos. Un nuevo capítulo de epistemologia teológico-pastoral: aportes a la compreensión de los signos de los tiempos. Atualidade Teológica, n. 58, p. 133-158, 2018.

SOBRINO, Jon. El principio-misericordia. Bajar de la cruz a los pueblos crucificados. Santander: Sal Terrae, 1992.

SOBRINO, Jon. Ressurreição da verdadeira Igreja. São Paulo: Loyola, 1982.

SOBRINO, Jon. Terremoto, terrorismo, barbárie y utopia: El Salvador, Nueva York, Afeganistá. Madrid: Trotta, 2002.

SOUSA, Ney; SBARDELOTTI, Emerson (Org.). Medellín: memória, profetismo e esperança na américa latina. Petrópolis: Vozes, 2018.

Horizonte, Belo Horizonte, v. 16, n. 50, p. 576-599, maio/ago. 2018 - ISSN 2175-5841 
TURSI, Carlos; FRENCKEN, Geraldo (Org.). Mantenham as lâmpadas acesas: revisitando o caminho, recriando a caminhada. Um diálogo de Aloísio Cardeal Lorscheider com O Grupo. Fortaleza: UFC, 2008.

VENTURINI, Lilian. Como está a desigualdade de renda no Brasil, segundo o IBGE. 30 nov. 2017. Disponível em:

<http://www.nexojornal.com.br/expresso/2017/11/30/Como-est\%C3\%A1-adesigualdade-de-renda-no-Brasil-segundo-o-IBGE $>$. Acesso em: 04 jul. 2018.

VILLAS BOAS, Alex; MARCHINI, Welder Lancieri. Medellín como recepção conciliar. In: SOUSA, Ney; SBARDELOTTI, Emerson (Org.). Medellín: memória, profetismo e esperança na américa latina. Petrópolis: Vozes, 2018. p. 110-121. 